\title{
Approaching and Implementing Civic Education Pedagogies and Engagement Values in the Moroccan Classrooms: Gender-Based Perspectives
}

\author{
Karima Mechouat \\ Assistant Professor Centre Régional des Métiers de l'Education et de la \\ Formation CRMEF. Fes-Meknès English Department. Morocco
}

doi: 10.19044/esj.2017.v13n7p259 URL:http://dx.doi.org/10.19044/esj.2017.v13n7p259

\begin{abstract}
Civic education and engagement in Morocco faces many obstacles which make any step towards democratization commitment a hard process. In the present paper, the urgent need to incorporate civic education values in the teaching/learning process in all disciplines in general and within the EFL classrooms in particular will be addressed, along with the effective pedagogies, techniques and the concrete strategies that can be deployed to ensure an efficient reinforcement of engagement values in the Moroccan school. The rationale behind the teaching of civic education is that the basic principles of this field, such as democracy, human rights, gender mainstreaming as well as freedom of speech are closely related to our teaching career. As an attempt to reflect my personal perspectives and the needs of our teacher trainees in our English department, three primary questions will be addressed: 1-To What End/Why? 2- What? 3- By What Means/How? These questions will attempt to offer a better understanding of the problem, approach civic engagement with a gender lens, and provide insights to the integration of civic education pedagogies in the Moroccan classrooms. As the study reveals, to ensure a rewarding implementation of the civics program and an efficient reinforcement of engagement and gendersensitive values, teacher educators, teacher trainees and all teacher practitioners should be familiar with the available resources and content relevant to civic-oriented education. Indeed, without educating the student community -the most vital component of society- on these principles and practices, the process will remain slow, vulnerable and unsustainable.
\end{abstract}

Keywords: Curriculum contents, cooperative learning, civic education principles, gender-sensitive education, teacher/student education 


\section{Introduction}

In the present paper, the urgent need to incorporate civic education values in the teaching/learning process in all disciplines in general and within the EFL classrooms in particular will be addressed, along with the effective pedagogies, techniques and the concrete strategies that can be deployed so as to ensure a rewarding implementation of the civics program and an efficient reinforcement of democracy, human rights and engagement values in the Moroccan school. The project outlines concrete strategies and actions for putting civic education values into practice in the major domains of education.

The rationale behind the teaching of civic education is that the basic principles of this field, such as human rights, gender mainstreaming; democracy, critical thinking as well as freedom of speech are closely related to our career: teaching English as a foreign language (TEFL). Based on my teaching experience, these principles are applicable in any school setting.

Therefore, my personal perspectives and values as well as the needs of our teacher trainees in our departments in the CRMEF will be reflected by addressing three primary questions:

1- To What End/ Why?

2- What?

3- By What Means/ How?

\section{To what end/why?}

Civic education and engagement in Morocco faces many obstacles which make any attempt towards sustainable democratization commitment a long way and hard process. This democratic deficiency is more essentially related to a feeble culture and practice and the lack of civic values and practices at grass-root levels. In fact, without educating the student community -the most vital component of society- on these principles and practices, the process will remain slow, vulnerable and unsustainable.

Through research and education in Moroccan universities, educational institutions, schools and teachers' training centres (CRMEFs and all Pedagogical Centres), this educational strategy has the potential to bring about a determinate momentum for change towards the implementation of civic education pedagogies and the mainstreaming of youth civic participation and engagement. It is noteworthy that no robust and comprehensive initiative has been undertaken in this direction so far.

However, in social studies and human sciences teaching affiliations, civic engagement is not critically approached, nor it is systematically incorporated. This accounts for the fact that no deep and comprehensive initiative has been undertaken in this respect. 
All this suggests the urgent need to initiate relevant research and promote more synergy between the committed agents and the targeted recipients and users of civic-oriented inputs.

As a matter of fact, the CRMEFs and all educational institutions as training and advocacy-based instrument present a fertile ground for innovative ideas and civic oriented-initiatives as well as an established platform for free interaction and communication with all stakeholders and decision makers. The use of ICTs as a leverage will bridge the gap between our educational institutions and make our CRMEFs, schools, and universities’ policies more integrative.

Therefore, by raising students' awareness of the importance of civic engagement and increasing their participation in local grassroots associations and advocacy as necessary conditions for the vitality of the democratization process in Morocco, it will be possible to overcome the current deficient situation. This will, undoubtedly, enable us to produce educated citizens who accept their obligations to all humanity, to making this a nation worth defending in a safe, peaceful and promising world.

Moroccan universities, educational institutions, schools and teachers' training centres are invited to open up on each other regardless of their different fields of specializations through the incorporation of multidisciplinary courses that cut across disciplines and integrate civic learning into their courses. Therefore, reinforcing the interdisciplinary and trans-disciplinary character of our educational programs will certainly refresh their attractiveness and widen students' horizons of expectations.

In respect with this view, we need to put in place service learning and training-based program to be able to train young people who are actively committed to their pedagogical engagement in the classrooms and their responsible participation in the social and political arenas. Thus, rethinking and reconstructing our teaching and learning priorities should be based on new frameworks and strategies that put both the teacher and the student in the realm of civic-oriented education.

Service to the community and service partnerships, and improving the quality of our school life and the lives of our students as well should be key elements of curricular and extracurricular activities. Such principles will provide the focus for much research in the CRMEFs and all other pedagogical training centres around issues such as civic oriented commitment, ethics and social integrity. In other words, CRMEFs and all teacher training centres should afford teacher trainees further opportunities and qualify them to make their expertise useful to their students in particular and their community at large.

Every teacher also needs to assume the role of researcher and critical thinker in order to analyze, understand and evaluate communication in his or 
her EFL classroom, for the purpose of introducing the necessary reforms and deploy the appropriate strategies required to meet the needs of the students.

The Civics Program enumerated below is designated to foster and support cross culture/gender communication, tolerance, citizenship, understanding, respect, cooperation, collaboration and solidarity. In the longterm I hope that the teachers involved and the students targeted in this project will remain committed to civic values and become aware and, thus, empowered to address fundamental issues that will resist all implicit trends towards sectarianism.

\section{What?}

\section{a- Multi-disciplinary civic education pedagogy and pluralism}

Morocco as a highly pluralistic nation represents a fertile field where civic education values might be learned by all teachers, using multidisciplinary pedagogies to understand citizenship formation. Teachers would learn how to integrate civic education as a matter of pedagogy and content through the use of useful pedagogical tools, such as: history as pedagogy and multidisciplinary and cooperative teaching. Such a practical approach which enhances sequential higher-ordered thinking skills within the teaching and learning process would facilitate collegiality. Meanwhile, it would promise to bridge actual gaps in civic learning which is mainly based on the main principles of cooperative/reflective teaching.

\section{b- Simulations and role play across disciplines}

Simulations and role play can be used as effective techniques to increase students' abilities to debate analytically and think critically, which will, undoubtedly, help students develop skills and competences that are applicable in real life situations and coursework. Thus, teachers who possess "a spirit of civic mindedness" are required to be highly qualified to carefully design activities that will be introduced as a teaching pedagogy to stimulate critical thinking and thoughtful leaning as main principles underlying important concepts of discovery and meaningful learning (See Bruner 1961 and Ausubel 1968). Indeed, Ausubel focused on meaningful learning as:

A clearly articulated and precisely differentiated conscious experience that emerges when potentially meaningful signs, symbols, concepts, or propositions are related to and incorporated within a given individual's cognitive structure. (Cited in Takač, 2008, p. 26).

This will pave the way for teachers and students alike to get deeper insights into their socio-cultural and political contexts. 
c- Strategies for gender responsive teaching and learning pedagogies and gender mainstreaming in the classroom c-1- Civic oriented-education and curriculum: Considering curriculum content with gender-based perspectives

The curriculum and accompanying learning materials should be created to achieve the main educational goals that are required to be set by the Ministries of education together with other ministries and relevant stakeholders. In fact, the review and development of the formal education curriculum should take into consideration students' needs to promote new life-saving and life-sustaining skills that are more essentially based on gender equality.

A careful analysis and review of the curriculum content should be gendered by considering male and female students' needs, and integrating gender dynamics to ensure an effective and appropriate learning. Examples of gender-based content targeting gender dynamics might include:

\section{c-1-1 Human rights, tolerance and peace education}

Curriculum content needs to promote gender equality and peace education principles with a focus on human rights, and in particular males and females' equal rights, with reference to the Convention on the Elimination of Discrimination Against Women (CEDAW) that presents an integrated framework for the protection of the full spectrum of women's human rights. Indeed, in conflict situation, conflict resolution, problem solving and peace-building contexts, curriculum content can address gender stereotypes and preconceived ideas that deteriorate women's image and misrepresent the polar concepts of masculinity and femininity as being mutually exclusive.

\section{education}

c-1-2- Life skills and sexual/reproductive health oriented

Most children and adolescents are left with little or no information on sexual and reproductive health. Such a deficiency emanates from the fact that most families and social networks in the new era of technology are disrupted. This suggests the urgent need to teach students life skills that will engage them in discussions involving gender dynamics and targeting gender issues, namely sexuality and reproduction. Exposing students to these issues and involving them in such debates will certainly raise their awareness and generate a demand for improving the quality of services, health standards and welfare.

A life skills approach may address outstanding issues in relation to sexual and reproductive health: the reproductive system; benefits of postponing marriage and pregnancy; avoiding maternal morbidity and mortality; nutrition; personal hygiene; prevention and treatment of HIV; care 
and support of people living with HIV and AIDS; addressing sexual harassment and violence.

Meanwhile, dealing with these topics as main contents of gendersensitive education should take into consideration the local culture of both teachers and students. This necessitates the importance of sustained and long-term coordination with all community education committees. It also entails secured support from important authorities, such as the Ministry of Health, the Ministry of Culture as well as the Ministry of Solidarity, Women, Family and Social Development in Morocco.

\section{c-1-3 Training skills}

As a direct result of gender stereotypes in the community and patriarchal ideologies that further reinforce unequal social status and income between the sexes, there are often gendered decisions made about which skills male or female learners select when they participate in vocational or skills training. Males will often receive training in professions that earn higher wages while females are usually trained for jobs that require nurturing and catering skills which, consequently, widen gender disparities in males and females income. Such training discrimination begins in the nursery where male and female infants are perceived and handled differently, and continues in the educational systems, where boys and girls are channeled into preparing for different occupations that are assumed to suit their nature. All these sorts of discrimination are unjust because they deprive women of opportunities for meeting their needs, proving their identities and equally attaining their potential. As a result of the continued operation of these gender- biased assumptions, even today, as Foucault puts it,

Women though enfranchised citizens, are handicapped by the fact that neither their socialization nor their training, neither the expectations placed on them nor the opportunities or rewards afforded to them in their adult lives are such as to enable them to achieve economic, social or potential equality with men. (1979, p. 92).

In Other words, instead of being socialized for active participation in citizenship, and instead of being fully integrated in the public space, women have been socialized to put home and private virtues ahead of public action.

Therefore, education practitioners and stakeholders should insure that career guidance, which challenges gender bias and targets the potentials and competences of each individual trainee, should be provided to subvert traditional gender roles and challenge all forms of gender discrimination in the job market. This initiative should also be based on market analysis and a 
careful reconsideration of the demand for contextually appropriate goods and services with a gender lens.

\section{c-2- Civic oriented-education and teaching/learning materials}

In addition to the analysis of curricula, the content of textbooks and other teaching materials should also be examined. Often we do not notice the gender and cultural discrimination that teaching and learning texts and images can portray, because, under the impact of the socialization process, we have become so used to seeing them. A gendered rethinking of the teaching and learning materials can be carefully done by raising important questions like:

- How frequently are male and female characters portrayed? e.g. do math, technology, language and science textbooks only include images and names of males? How are the male and female characters portrayed? e.g. are only females shown doing housework? How are roles and relationships between males and females portrayed? e.g. is the mother routinely giving instructions to her children? is the father always disciplining the children? Which adjectives are used to label male and female characters? e.g. are females ever referred to as strong and independent? Are males ever referred to as caring and sensitive?

We need to move towards developing gender-sensitive teaching materials and textbooks that show boys and girls, women and men, in a variety of roles (e.g. men cooking, women driving cars, etc.) so as to promote gender equality and deconstruct male's dominance which is, as Pierre Bourdieu argues: "so deeply rooted in our collective unconscious that we no longer even see it. It is so in tune with our expectations that it becomes hard to challenge it". (1998).

Therefore, teachers are required to ensure that language and pictures do not reinforce gender stereotypes and disseminate distorted images of both sexes.

As a means to successfully enhance a gender-responsive approach in the teaching and learning process, teacher training should be more essentially based on teachers' awareness of gender stereotypes. It should qualify them to evaluate, adapt and use teaching materials for positive effects and critically rethink all gender misrepresentations by prompting open questions about the content.

\section{d- Civic education-based content and processes for pre-service teacher training program}

The revitalization of teacher training institutions and university education facilities requires much effort on the part of all educational authorities. This educational initiative should dedicate enough time and implement more strategies to train and support all teachers and other educational personnel. 
Pre-service and service-training content and process should be responsive to gender equality principles and civic education values that aim at equipping teachers with life skills and competences and equally qualifying them to support gender-sensitive and human rights-oriented education.

\section{d-1- Content}

Teacher training content represents the basic component of any professional development-responsive training. Indeed, content areas of teacher training that aim at mainstreaming civic education values and enhance teachers' awareness of gender issues may include:

- Pedagogy and teaching methodologies, including gender sensitive learning processes, positive discipline as well as classroom management approaches of the teaching and learning process. All this necessitates a cautious reconsideration of preliminary codes of conduct for teachers and other education personnel, such as the condemnation of gender discrimination and gender-based violence against learners, the banning of inappropriate reporting and referral mechanisms and human rights abuse prohibition. Therefore, content areas training will be tailored to comprise a deeper understanding of a humanitarian law with all its human rights facets and gender-based perspectives.

- The availability of local services and referral systems responsive to both teachers and students' needs for appropriate psychological development and support.

Both a gender-sensitive and human rights-responsive planning of teacher training processes should include the following issues:

- The need to create a balance of male and female teacher practitioners entails that teacher trainers should also be gender balanced and aware of civic education values and human rights principles.

-Constructing a gender-based approach that integrate men as equal partners to women can build respect and support women's experiences and position and, thus, challenge all ideological attempts to perceive any support and development initiative targeting women as being either 'women's problems' or 'privileges for women'.

\section{d-2- Processes}

As part of teacher training planning processes, larger teacher training needs assessments requires that education practitioners in particular, together with national education authorities and stakeholders at large, should consider teachers' awareness of civic education issues.

Teachers as education practitioners play an outstanding role in improving the quality of education overall. Teachers training processes should be based on teaching approaches that guarantee quality education based on equality principles. As a matter of fact, quality education that 
enhances gender-sensitive, participatory and inclusive cooperative learning should also target the following issues:

- Teachers should be alert to any gender and race stereotypes, human rights abuse in textbooks and all learning materials, and use this positively in civic values-sensitive teaching. In line with this view, teachers can openly question the materials and encourage critical and analytical thinking in terms of civic education principles.

- To guarantee an effective management of the teaching and learning process, teachers should be qualified to adapt classroom seating arrangements to the classroom context and to students' needs. Indeed, teaching strategies can be modified to equally integrate males and females in classroom discussions and activities. Where culturally appropriate, teachers can use cross-sex groupings or pairings to encourage equal contributions to the learning process. This, however, does not suggest that single-sex learning spaces are not desired options in some contexts.

- Teachers can use the students' different life experiences as a starting point for designing activities and teaching new things, e.g.to raise discussions on why life experiences become gendered and how girls and boys can notice when difference becomes discrimination, exclusion and marginalization. .

- Teachers and learners alike should be aware of the violent and abusive language that humiliates or degrades either sex.

-Teachers need to use teaching approaches and methods that boost students' self-esteem and self-confidence, bearing in mind that all learners, regardless of their sex, require more reassurance to feel comfortable.

\section{By what means/how?}

\section{Strategies and techniques for teaching/learning civic education} principles in the classroom language

Civic education encompasses the subject matter of lessons (content), the classroom atmosphere and patterns of classroom interaction (the way the teaching/learning process is planned and managed), as well as the quality of the students' learning that should transcend the space of the classroom to reach his/her life-long learning and competences outside school.

The classroom provides a very intimate setting for the cultivation of democratic ideas among male and female youth and a fertile ground for the implementation of civic education pedagogies. Within the school curriculum, the history, principles, and practice of democracy may be treated as a distinct course of study or integrated into a number of other disciplines, such as history, sociology and language.

Therefore, more than being merely a simple inclusion of lessons about human rights in history, language, human studies, Islamic studies 
classes and other disciplines, civic education represents the act of recognizing the student as a full human being in all aspects of teaching and learning. The ultimate goal of this civic-oriented and life-long learning is to create autonomous and responsible individuals who can make decisions for themselves.

The need to implement civic education in the EFL classroom is part of a broader approach to education that incorporates all these factors and also involves the various participants concerned with educating young people for effective and responsible citizenship, including parents, educators, and policy-makers, in addition to all governmental and non-governmental organizations. In this respect, Tourney-Purta, Schwille, and Amadeo (1999, p. 30) report that civic education should be cross-disciplinary, participative, interactive, related to life, conducted in a non-authoritarian environment, cognizant of the challenges of social diversity, and co-constructed with parents and the community and (non-government organizations) as well as the school.

As discussed below, these components of civic education have important implications for the content, interactions, activities and classroom arrangements in the EFL classroom. Such an outstanding connection between learning and citizenship includes language education. In fact, teachers of English as foreign language (EFL) practitioners should be involved in the discovery of how to best contribute to the development of knowledgeable and responsible citizens.

In respect with this view, the issues of preparing students in the language classroom to be effective citizens will be closely addressed, along with the knowledge, skills, and values required for civic education. The paper will suggest how these principles can be applied to EFL teaching and learning, particularly by considering (a) the selection of content, (b) teacher and students' roles, (c) the teacher as a motivator, (d) teacher's education, (e) classroom activities and seating arrangements.

\section{a- Selection of content}

The selection and organization of educational content is an excellent way to directly convey civic education values in the language classroom. For example, some topics that reflect good citizenship are human rights, gender and racial discrimination/equality, gender mainstreaming and socio-cultural and linguistic diversity, peace and tolerance, cooperation and solidarity. One way to evoke these topics is to explicitly teach the cultural components of language. This is likely to foster in the student a tolerant attitude towards the second language, its speakers and its culture, which will in turn make the students value their own culture and identity. About this point, Ouakrime asserts that, cross-cultural understanding is a two-way process that creates learners who: "are engaged to develop not only a tolerant attitude towards 
the target culture and members of the target culture community, but also a positive attitude towards their own culture”. (1995, p. 29).

On the other hand, because of the importance of English as an international language, there is a risk that learners will reject their own cultures. This culture/identity clash can be avoided by choosing appropriate content. As Patrick states, an essential element of good civic education is achieved when the teacher creates a democratic ethos by discussing a relevant topic in a classroom environment that: "is conductive to and supportive of a free exchange of information and ideas" and "where there is mutual tolerance for diverse opinions" and "respect for the dignity and worth of each person in the group”. (2003, p. 7).

Therefore, Content that allows serious discussion and debate about substantive social and global issues will encourage students to consider all sides of an issue and develop critical skills that transfer outside of the classroom. Rather than packing information and stuffing their minds with factual details, students should acquire the ability to compare, contrast, interpret and extrapolate. They should be motivated to engage into negotiable rapport with the content from the other culture and avoid preconceived ideas and taken for granted facts. In this respect, Ennaji asserts that: "integrating multiculturalism and citizenship issues may develop critical thinking, empower students to take action for problem solving, and develop their awareness of citizens' issues and global issues”. (2009, p. 22).

In fact, a learner-centered approach in educations is basically based on the principle that language is no longer perceived as a packaging of knowledge, rather it is now seen as an ongoing process of investigating and assessing of facts to promote students' intercultural competence which entails a change from transmission pedagogy to analytical, critical and reflective thinking.

Within the new era of technology and globalization, culture and language relationship is no longer fixed. It is subject to ubiquitous reconstructions stimulated by the global and local inflections. In this regard, Pal (2002, p.124-129) states that the local nowadays, appropriates, transforms and adjust to the global models as a response to the local communities' requirements. It is a kind of transculturation by which people reconstruct the meaning of the global and tradition is retained. This makes the culture and language rapport "fluid and dialogic", which requires the students to "negotiate new modes and tools of communication in accordance with changing circumstances and purposes" (Findlow, 2006, p. 22).

It's high time to equip our students with the necessary tools and civic-oriented values to think globally and act locally. 


\section{b- Teacher/student's roles}

In the traditional language classroom, students and teachers often have defined and fixed roles. In highly teacher-controlled classrooms all patterns of communication become teacher-oriented. This, unfortunately, does not encourage students to assume an active participatory role and does not foster, or rather, stands as a cobblestone to the development of interaction skills and communication competences as essential elements of citizenship.

The optimization of civic education pedagogies in EFL classrooms entails the need to design more student-engaging and motivating activities and establish patterns of communication which are more predisposed to students' active participation and engagement in the learning process.

In fact, the implementation of the principles of citizenship in education depends crucially on teachers' successful management of/and learners' active engagement in EFL classroom interaction. Therefore, teachers and learners should contribute to the establishment and maintenance of a cooperative and collaborative rapport. Teachers need to create an environment that is conductive to learners' practice of different participatory and intellectual skills. As teachers relinquish the controlling role and recognize students' effective contributions to their learning, teachers and students alike become equal collaborators in the teaching/learning process (Lynch, 1996).

The focus on the learner's active and participatory role in the classroom activities does not imply that the teacher' job is an easy one. On the contrary, the teacher who intentionally relinquishes his/her dominant role as the source of knowledge and begins to empower students has even more responsibilities, including roles as coordinator, manager, monitor, organizer, mentor, consultant, counselor, moderator, and adviser. All these roles of a teacher who oversees a learned-centered classroom make him/her a facilitator of the teaching/learning process (Littlewood, 1981). It is worth mentioning that this role of the teacher is similar to the role of the facilitator in non-formal education and training contexts. As Owen and Saddler explain, "the job of the facilitator is to create a safe space within which people can work and then get out of the way". (1999, p. 14). For teachers, this suggests that they need to establish a relaxed and safe atmosphere in the classroom where students share reciprocal responsibility for conducting classroom interaction, communication and management.

\section{c- The teacher as a motivator}

Motivating students to take an active role in their learning requires that the negative impact of the traditional and formal nature of the classroom and its institutional context, characterized by rigid disciplinary routines and the strict distribution of roles, should be minimized to its lowest level. 
Many students have preconceived ideas about classroom roles; such students might expect the teacher to assume total responsibility for their learning, their achievement, and for classroom management. This entails that teachers' most important responsibility is to deconstruct these attitudes and subvert the traditional roles of both teachers and students in the classroom.

Teachers need to effectively deploy different strategies to motivate students and provoke their interest so as they can engage in classroom discussions and interactions. For instance, teachers can use icebreakers to involve unmotivated and shy students or uninterested sub-groups in classroom activities. Teachers should be qualified to make use of a variety of techniques for an effective management of the teaching and learning process. $\mathrm{He} / \mathrm{she}$ can create an atmosphere of familiarity, friendship, cooperation, and mutual trust in the classroom through group work, pair work, and collaborative class discussions where students engage in purposeful communication that promotes their participatory skills and their sense of responsibility and independence. Thus, instructional groupings and seating arrangements techniques, when used appropriately in any classroom context, stimulate students' motivation to engage in all civic-oriented activities and equally enhance their active learning.

\section{d- Teacher's education}

No one can successfully teach specific knowledge, skills and virtues to students if he or she has not learned them. Therefore, knowledge of the Why, What and How of civic education and engagement values requires teachers' pre and in-service professional training.

As a matter of fact, teachers' training and professional experiences should be consistent with civic education values, which helps them shape their perceptions and beliefs about education in general and language education in particular, and makes them capable facilitators and counselors in the language classroom. Every teacher also needs to assume the role of researcher in order to evaluate and understand communication in his or her EFL classroom, for the purpose of introducing the necessary changes and appropriate tools required to meet students' needs and expectations.

Therefore, an appropriate professional training in civic education with all its human rights facets and gender perspectives as well as a high degree of motivation and intellectual and pedagogical commitment on the part of every teacher is likely to help reach the desired outcomes.

\section{e- Classroom activities and seating arrangements}

Developing a sense of citizenship in students demands classroom activities that will allow them to exchange ideas with one another, express their opinions, and develop learning strategies and communication skills for successful negotiation. Therefore, small group work represents a critical 
element of civic education that will create interactive patterns of classroom communication.

\section{e-1- Group work and learning}

*Cooperative Learning: Group work provides opportunities for students to be involved in cooperative classroom communication. It equally helps create a stress-free and motivating atmosphere in the classroom (Cooperative Learning) since students work together in small groups instead of competing for recognition or grades. Moreover, each member of the group has something unique to contribute which enables the students relate to one another more easily than to a teacher.

Group work activities have the advantage of engaging students in interactive communication and negotiation of meaning that promotes associated participatory skills and the virtues of tolerance and mutual respect necessary in citizenship education.

Cooperative learning as an instructional approach suggests effective ways of reducing competition and increasing cooperation among students so as to diminish hostility, prejudice, and patterns of failure among students. It teaches social skills such as cooperation, teamwork, and communication skills useful in later life. Therefore, students learn how to work and how to problem solve together to achieve a common goal which is more essentially required in the workplace.

However, it is not enough to simply tell the students to work together; teachers need to:

- Be aware of all cognitive, social, cultural and gender disparities of their students;

- clarify learning goals, students’ roles, and expectations;

- divide resources and students’ roles within and among groups;

- provide tasks and rewards that promote team spirit;

- provide some kind of incentives and recognition for individual achievement.

*Learner-Centeredness: Group work activities require learners to actively and creatively engage in all participatory activities and equally assume a high degree of contribution and responsibility in their learning (Learner-Centered Approach). Thus, group work activities are also learnercentered. According to Nunan (1988), some learner-centered activities include:

-Role plays and simulations: Learners are assigned to play a part in a certain social situation and express to a partner or partners what they think and feel;

- Problem-solving activities: Learners are presented with a scenario and asked about their opinions, experiences and what they would do in a particular situation. 
- Information-gap activities: Learners exchange information with their partners to solve a problem or collect information.

- Opinion-gap activities: Learners share or defend their attitudes, opinions, or preferences about an idea with their partners.

These activities are learned-centered and motivating; they help students recognize that there exist multiple ways of perceiving things and that communication involves a give-and take process that is an essential element for resolution. They also provide students with ample opportunities to actively engage in classroom interactions involving a high degree of negotiation and critical thinking that will help them promote the participatory and intellectual skills necessary for effective citizenship.

In group work as a classroom dynamic the "major defining characteristic in terms of participation is that the learner is primary speaker" (Van Lier, 1988, p. 173). In other words, students share responsibility for the management of interaction in communication tasks that empower them by putting them in control (Nunan, 1988).

Small groupings enhance student cooperation and social skills. Moreover, appropriate group experiences promote a deep understanding of gender and social differences among people as well as an appreciation of cultural pluralism, and, thus, fosters the development of democratic and engagement values.

\section{e- 2- Whole Class Discussion and learning}

An EFL teacher who encourages open communication through whole class discussion qualifies the learner to acquire citizenship knowledge and skills as well as the values of mutual respect, tolerance, open-mindedness, coexistence, cooperation, collaboration and solidarity. Using whole class discussion as an important technique of instructional grouping provides learners with invaluable opportunities to engage in classroom negotiations and to share responsibility for a successful management of classroom interaction.

For the whole class discussion as a classroom dynamic, Littlewood suggests that an informal circular arrangement of students "can help greatly to reinforce the learners' equality as co-communicators”. (1981, p. 45). Owen agrees that a circle enhances open human communication because "in a circle, people can simply be with each other face-to-face", in contrast to rows, where they "face the source of power and authority, and it is clear who will talk and who must listen" (2008, p. 5).

All this suggests that, in addition to small group work, whole class discussion also allows students to freely engage in interactive communication while they express themselves and exchange ideas and information. 


\section{Recommendations and implications}

Given the urgent need to implement civic education values in the EFL classrooms in particular, and the Moroccan educational program at large, I suggest incorporating the following tips to teach civic education in our school:

Civic education should be integrated within students' learning experience by:

a- Encouraging students' freedom of expressions through systematic speaking and writing activities: presentations, debates, workshops, class and school magazines.

b- Creating simulations of different new roles. Example: to subvert traditional roles of students/teachers(students as leaders and decision-makers and teachers as counselors and consultants); males and females involved in newly subverted gender roles (men being involved in the domestic chores and, thus, assuming the responsibility of child-rearing and housekeeping and women portraying the positive image of breadwinners, performing different intellectual tasks, etc.).

c- Initiating elections for students' government and forming (a) club(s) by giving them the opportunity to choose their class leaders.

d- Empowering students to form their committees, project group and action plans and increasing their motivation to engage in various civicoriented activities.

e- $\quad$ Encouraging volunteer work in the community (school and society at large): planning more social events and involving parents in all volunteer and participatory work initiatives, which will boost both students and parents' spirit of civic-mindedness.

f- Liaise with colleagues and students from other schools and educational institutions and encourage the inter/trans-disciplinary character of their education specialization.

All in all, preparing students to be effective citizens by applying the principles of civic education is a broad educational endeavour and a long way process of which language education, gender awareness and human rights sensitization represent an indispensable part.

\section{Conclusion}

Throughout this paper, the urgent need to incorporate civic education values in the teaching/learning process in all disciplines in general and within the EFL classrooms in particular has been closely addressed. The project outlines concrete strategies and actions for putting civic education values into practice in the major domains of education.

To ensure a rewarding implementation of the civics program and an efficient reinforcement of democracy, engagement and gender-sensitive 
values in the Moroccan school, teacher educators, teacher trainees and all teacher practitioners should be familiar with the available resources and content relevant to civic and gender-oriented education and a range of good practice case studies gleaned from other teacher education institutions. Meanwhile, they are to become familiar with action research methodologies and be able to engage with peers in cooperative teaching and reflective practice as well as a continuous training and improvement approach to integrating gender responsive values and civic understanding in teacher education for sustainability.

Throughout a careful consideration of the content that EFL teachers select, the activities they engage in, and the type of classroom arrangements and interactions that occur in their classrooms, all civic education principles can be successfully implemented. The main goal is to increase students' active interaction in the classroom as they develop communication strategies as well as all participatory skills and negotiation competencies necessary for a successful citizenship-based education. It also promotes within students a sense of responsibility for the learning process. Acting as a facilitator while adhering to citizenship, human rights, gender equality principles and civic education values, and actively motivating students, an EFL instructor who possesses a sense of "civic mindedness" can create an environment in which students become collaborative citizens. These citizens are qualified to practice mutual respect, understanding and tolerance, and transmit the civic values-based discourse to outside-school interaction.

\section{References:}

1. Ausubel, D. P. (1968). Educational psychology: A cognitive view. New York, NY: Holt, Rinehart \&Winston.

2. Ausubel,D. P. (2000). The acquisition and retention of knowledge: A cognitive view, Kluwer Academic Publishers. ISBN $\underline{9780792365051}$

3. Bourdieu, U. P. (1998). On male domination. Retrieved from http://www.Lemonde.diplomatique.htm.1998.com.

4. Bruner, J. S. (1961). The act of discovery. Harvard Educational Review 31 (1): 21-32.

5. Ennaji, M. (2009). Multilingualism, citizenship and education. Mediterranean J. Educ. Stud. $\quad$ 14(1):5-26. University of Malta: Printed at Impressions. Retrieved from http://www.Um.edu/mt/_data/assets/pdf_file/0005/77045/Med_Journ al_09Ennaji.pdf

6. Foucault, M., Foucault, M., \& Foucault, M. (1978). The history of sexuality. New York, NY: Pantheon Books. 
7. Littlewood, W. (1981). Communication language teaching. Cambridge: Cambridge University Press.

8. Lynch, T. (1996). Communication in the language classroom. Oxford: Oxford University Press.

9. Nunan, D. (1988). The learner-centred curriculum. Cambridge: Cambridge University Press.

10. Ouakrime, M. (1995). Purposes of ELT in Morocco revisited. In Education for development: The role of English as a foreign language. Proceedings of the $15^{\text {th }}$ Mate annual conference, ed. S. Diouny and E, A. Imad; 27-30. Casablanca, Morocco. Retrieved from http;//www.matemorocco.infrance.com/Issue_95.pdf

11. Owen, H., \& Stadler, A. (1999). Open space technology. In P. Holman \& T. Devane (Eds.), The change handbook: Group methods for changing the future (pp. 233-44). San Francisco: BerrettKoehler.

12. Owen, H. (2008). Open space technology: A user's guide. $3^{\text {rd }}$ ed. San Francisco: Berret-Koehler.

13. Patrick, J.J. (2003). Essential elements of education for democracy: What are they and why should they be at the core of the curriculum in schools? Paper presented in Sarajevo, Bosnia and Herzegovina. Calabasas, CA; Centre for Civic Education. Retrieved from http://www.CivicEducation.org/pdf/EEOEforDemocracy.pdf

14. Takač, P. V. (2008). Vocabulary learning strategies and foreign language acquisition. multilingual matters. Clevedon. ISBN 9781847690388.

15. Tourney-Purta, J., Schwille, J., \& Amadeo, J. (1999). Mapping the distinctive and common features of civic education in twenty-four countries. In J. Tourney-Purta, J. Schwille \& J. Amadeo (Eds.), Civic education across countries: Twenty-four national case studies from the IEA civic education project (pp. 11-35). Amsterdam: IEA.

16. Van Lier, L. (1988). The classsroom and the language learner. New York, NY: Longman. 